\title{
Моделювання електроерозійних процесів на графітових електродах при формуванні наноструктур у плазмовому середовищі
}

\author{
Національний аерокосмічний університет ім. М. Є. Жуковського \\ «Харківський авіаційний інститут»
}

\begin{abstract}
У роботі розглянуто теоретичну модель ерозійних процесів у плямах електродів під час вакуумного розряду при формуванні наноструктур. У наведеній моделі докладно розглянуто джерела та стоки тепла в електродних плямах. Так для катода враховано густину теплового потоку, який створюється іонами 3 урахуванням емісійного охолодження, зворотного електричного струму і тепла Ноттінгема, а при опису поверхневим джерелом тепла для анода, розглянуто як позитивний анодний спад потенціалу, так і негативний. При опису об'ємного джерела тепла було досить докладно розглянуто розподілення густини струму в елементі розглянутого обсягу електроду. Для більш ємного опису рівняння теплового балансу було розглянуто теплопідведення від випромінювання плазми і конвективного теплообміну, та тепловідведення внаслідок зсуву фронту випаровування плазми й її випромінювання. Також було враховано тепловий потік, що відводиться завдяки переміщенню плями. Завдяки запропонованій моделі було визначено температурні поля поблизу плям та швидкості випаровування матеріалу за час життя плями, що в свою чергу дало змогу визначити коефіцієнт ерозії для електродної плями. За запропонованою моделлю було проведено розрахунки для графітових електродів. Отримано залежність коефіцієнта ерозії від часу житті плями та густини струму на електродах. Визначено, що при густині струму більше $10^{11} \mathrm{~A} / \mathrm{m}^{2}$ збільшується імовірність появи викиду матеріалу у вигляді кластерів, що буде запобігати появі наноструктур. Залежності коефіцієнта ерозії від часу життя було отримано як для стаціонарної плями, так і для рухомої. Отримані залежності свідчать про суттєве зменшення коефіцієнта ерозії при підвищенні швидкості плям. Визначені теоретичні значення за густиною струму збігаються за порядком 3 експериментальними значеннями. Модель можна використовувати для визначення критичних значень технологічних параметрів при отриманні наноструктур для різних матеріалів електродів. Ключові слова: електрод, вакуумна дуга, електродна пляма, електроімпульсна ерозія, наноструктури.
\end{abstract}

\section{Вступ}

Постійний інтерес вчених до плазмових технологій ґрунтується на досить широких можливостях їх використання, наприклад для осадження тонких металевих плівок $[1,2]$, генерації лазерної плазми $[3,4]$ або як джерело енергії для космічних плазмових двигунів [5, 6]. Численні дослідження процесів, які відбуваються у плазмовому середовищі $[7,8]$, та їх параметрів $[9,10]$ дають нові можливості для удосконалення технологій та їх використання. 3 урахуванням постійно зростаючого інтересу виробників до нанотехнологій та наноматеріалів на особливу увагу заслуговують питання, пов'язані з отриманням наноструктур у плазмовому середовищі при використанні вакуумної дуги, наприклад при вирощуванні нанотрубок [11], створенні наноструктурованих плівок [12] або одержанні наноструктурованих покриттів [13, 14].

Процеси, які проходять у вакуумній дузі, розглядалися досить докладно [15]. Так, у [16] було розглянуто катодні та анодні процеси як з холодними, так i гарячими електродами, а також деякі процеси у міжелектродній плазмі. Також 
розглядалась втрата матеріалу електродами у вигляді пари при високих значеннях іонного струму [17], що сприяло створенню струменів у катодних плямах. Проводились вимірювання густини іонного струму у вакуумній дузі 3 використанням тугоплавкого анода [18] та розглядалась еволюція температури анода у вакуумній дузі $[19,20]$.

Дослідження катодних та анодних плям у вакуумній дузі пов'язані з їх переважним впливом на якість дугових технологій. При дослідженні дуги у поперечному магнітному полі [21] було розглянуто групування катодних плям та їх зворотний рух. Досліджування групових катодних плям при імпульснопідсиленому вакуумно-дуговому напиленні [22], показало вплив високоімпульсного струму на емісію електронів, що сприяє більш високій швидкості розширення плям. Дослідження формування та поведінки плазмових плям на поверхні плівок титану [23, 24] показали, що плазмові плями і щільною серцевиною виникають у результаті взаємодії мікроскопічних вихорів у плазмовому каналі та виникаючого магнітного поля вздовж електрода, що може спричинити спіралеподібний струм плазмової плями. При дослідженні розряду імпульсної вакуумної дуги з композитним катодом (дейтерид цирконію) [25] було показано, що основним постачальником іонів у дуговому розряді мікросикундної довжини є катодні плями. А розгляд еволюції вакуумної дуги з наносекундним розділенням [26] показав, що канал між електродами створюється у формі катодної плазми задовго до того, як в аноді розвинеться значна активність. Проводилися також і деякі теоретичні дослідження, так, у [27] було розроблено статистичну модель вакуумної дуги для опису ефекту самочинного гасіння, завдяки якій показано циклічний характер процесів катодних плям і показано самопідтримуючі властивості дуги завдяки вибуховій емісії.

Значно менше приділялось уваги процесам на електродах вакуумної дуги при фрормуванні наноструктур у плазмовому середовищі. Так, у [28] проводилось моделювання дугового розряду на мідних катодах, а у [29] дослідження впливу електричних та магнітних полів у дуговій плазмі при синтезі одностінних вуглецевих нанотрубок. Проведено також експериментальне дослідження впливу товщини наноструктурованого шару на фрізичні властивості вольфррамового катода [30, 31] та швидкість ерозії на наноструктурованих мідних катодах [32]. Проводились і деякі дослідження дугових плям [33, 34]. Так на електродах з наноструктурованого вольфраму було показано, що ширина сліду дуги збільшується зі збільшенням товщини наноструктурованого шару.

I хоча процеси на поверхнях електродів під час роботи вакуумної дуги вивчались досить докладно [12, 15, 17], подальші дослідження показали [35], що деякі наноструктури у плазмовому середовищі можна отримувати на інших, досить жорстких режимах з використанням тугоплавких електродів. Тому досить актуальною $€$ побудова тривимірної теплової моделі ерозійних процесів на графітових електродах. Це дозволить більш точно визначити критичні режими та вказати на нові можливості при фрормуванні наноструктур у плазмовому середовищі.

\section{1. Теоретичний розгляд процесів}

У роботах [35, 36] було показано, що основні ерозійні процеси при проходженні розряду в різних середовищах реалізуються в основному в електродних плямах. Тому формування моделі ерозійних процесів на електродах почнемо з розгляду процесів в електродних плямах. Дослідження 
ерозійних процесів при фрормуванні наноструктур у плазмовому середовищі почнемо з розгляду джерел і стоків тепла в електродних плямах, після цього проведемо аналіз результатів розрахунку. Зручніше за все теплові процеси моделювати, використовуючи рівняння теплового балансу.

Як було показано у [35,37], об'єм і напрямок перенесення тепла від плазмового стовпа розряду в тіло електрода, значно впливають на процеси біля електродних плям і механізм ерозії матеріалу електродів. Також розглянемо можливі джерела і стоки тепла в електродах як з нерухомими плямами, так і 3 плямами, що переміщуються 3 деякою швидкістю. В експериментальних дослідженнях [30,31] було показано, що на електродах присутні як ті, так і інші види плям.

Використовуючи загальне рівняння теплового балансу в одиничному об'ємі електрода [37], розглянемо докладніше джерела тепла на поверхні електродів, які виникають внаслідок перенесення енергії частинками.

Густина теплового потоку внаслідок бомбардування іонами поверхні катода подамо таким виразом:

$$
q_{i}=J_{\kappa}\left(U_{\kappa} \cdot \mu_{i}+U_{i}\right) \rho_{\kappa} /\left(1+\rho_{\kappa}\right),
$$

де $\mu_{i}$ - коефіцієнт акомодації іона в матеріалі катода; $p_{k}=J_{i} J_{e}$ - частка іонного струму на катоді; $U_{k}$ - катодний спад потенціалу; $j_{k}$ - повна густина струму на катоді; $U_{i}$ - потенціал іонізації бомбардувального іона; $j_{i}$-густина іонного струму на катоді.

Як було показано у [31], охолодження поверхні катодної плями здебільш здійснюється завдяки емісії електронів, при цьому густина теплового струму, що відводиться електронами, визначається формулою

$$
q_{e}=\left(A_{i}+\left(e^{3} E\right)^{\frac{1}{2}}+2 k T(0, y, z, t)\right) j_{e} / e,
$$

де $A_{e}$ - робота виходу електрона; $j_{e}$ - густина електричного струму на катоді.

Для визначення теплового потоку, що створюється зворотним електричним струмом, скористаємося таким виразом:

$$
q_{p . e}=\alpha_{e}\left(U_{\kappa}+2 k T_{e}\right) n_{e} v_{e} \exp \left(-\frac{U_{\kappa}}{k T_{e}}\right) / 4 e,
$$

де $\alpha_{e}$ - коефіцієнт акомодації електрона; $T_{e}$ - температура електронів; $v_{e}$ швидкість електронів, що визначається за максвеллівським розподілом частинок за швидкостями; $n_{e}-$ концентрація електронів.

Тепло на катоді при автоелектронній емісії (тепло Ноттінгема) може також робити значний внесок у поверхневе джерело тепла [31, 37], оскільки що виділяється безпосередньо на імітуючій поверхні та сприяє збільшенню густини теплового потоку:

$$
q_{H}=9,3 \cdot 10^{-1} \mu_{y} E \sqrt{A_{e}} j_{\kappa}(0, y, z, t)\left(\frac{1}{\beta_{\kappa}+1}\right)
$$


де $E$ - напруженість електричного поля поблизу катода, В/м; $A_{e}$ - робота виходу електрона, $\epsilon \mathrm{B} ; \mu_{y}$ - коефріцієнт посилення напруженості електричного поля.

Тепло Ноттінгема може бути значним для поверхні шорсткого катода 3 високим коефіцієнтом посилення напруженості електричного поля при відношенні висоти шорсткості до радіуса підстави порядку 100...200, а коефіцієнт посилення досягає 501/4100. У той же час для звичайних катодів за відсутності напруженості електричного поля внаслідок шорсткості або незначних зусиль тепло Ноттінгема створює додаткову густину теплового потоку, що становить величину від часток до 3 \% від густини теплового потоку внаслідок бомбардування іонами катода. Густина теплового потоку для катода, який створюється іонами з урахуванням емісійного охолодження, зворотного електричного струму і тепла Ноттінгема, визначимо так:

$$
Q_{K}=q_{i}-q_{e}+q_{p . e}+q_{H}
$$

У той же час для анода густина теплового потоку, що створюється поверхневим джерелом тепла при позитивному анодному спаді потенціалу:

$$
Q_{A}=j_{a} \mu_{a}\left(\frac{2 k T_{e}}{3}+U_{a}+A_{e}\right),
$$

де $j_{a}$ - щільність струму на аноді; $U_{a}$ - падіння потенціалу поблизу анода; $T_{a}$ температура електрона.

А для негативного анодного спаду потенціалу вираз для густини теплового потоку, що враховує дію іонного і електричного потоків на поверхню анода, набуде вигляду

$$
Q_{A}=j_{a}\left\{\frac{5 k}{2 l}\left(T_{e}-T(0, y, x, z)\right)+\frac{j_{a f}}{j_{e}}\left[U_{i}+\left|U_{a}\right|+\frac{5 k}{2 l}\left(T_{i}-T(0, y, z, t)\right)\right]+A_{e}\right\},
$$

де $T_{e}, T_{i}$ - температура електронів та іонів поблизу катода; $j_{e}, j_{i}$ - густина іонного і електричного струму на аноді; $A_{e}$ - робота виходу електрона з матеріалу анода; $j_{a f}$ - густина повного струму на аноді.

Слід зазначити, що всі величини у виразах (4) - (7) під час життя плями залежно від параметрів у зоні поблизу електронів матимуть незначні відмінності.

Для дослідження теплообміну в зоні електродної плями треба задати об'ємне джерело тепла. Так, в [31] розглядається об'ємне джерело тепла, що має постійну інтенсивність і певний тілесний кут розтікання струму. Ці пропозиції істотно спрощують розв'язання задачі теплообміну в зоні електродної плями. Для опису розтікання струму в зоні електродної плями скористаємося рівнянням Лапласа:

$$
\left(\frac{\partial^{2} \varphi}{\partial x^{2}}+\frac{\partial^{2} \varphi}{\partial y^{2}}+\frac{\partial^{2} \varphi}{\partial z^{2}}\right) / \rho[T(x, y, z, t)]=0,
$$

Граничні умови для цього рівняння:

1. На границі $x=0, j_{k}=\frac{1}{\rho[T(x, y, z, t)]}\left(\frac{\partial \varphi}{\partial x}\right)$ при $\sqrt{x^{2}+y^{2}}<0$;

$$
j_{a}=\frac{1}{\rho[T(x, y, z . t)]}\left(\frac{\partial \varphi}{\partial x}\right)
$$


та дорівнює нулю при $\sqrt{x^{2}+y^{2}}>R$.

2. На границях $x=x_{k} ; y=y_{k}, y_{n} ; z=z_{n}, z_{k}$

$$
\begin{gathered}
-\frac{\partial \varphi_{0}}{\partial \varphi}=\rho\left[T_{N}\right] j_{0} ; \\
j=j_{0}=\left(j_{k, a} \pi R_{n}^{2}\right) /\left(2 X_{k}\left(Y_{k}-Y_{n}\right)+2 X_{k}\left(Y_{k}-Z_{n}\right)+\left(Y_{k}-Y_{n}\right)\left(Z_{k}-Z_{n}\right)\right),
\end{gathered}
$$

де $\rho[T(x, y, z, t)]$ - питомий електричний опір, залежний від температури; $\varphi_{o}$ потенціал точки електрода; $R_{n}$ - радіус електродної плями на катоді або аноді; $X_{k}, Y_{k}, Y_{n}, Z_{n}, Z_{k}$ - координати межі розглянутої області простору.

3 урахуванням сказаного густина струму в елементі розглянутого об'єму визначимо так:

$$
j(x, y, z, t)=\frac{\left(j_{k, a} \pi R_{o}^{2}\right)}{\rho[T(x, y, z, t)]}\left[\frac{\partial^{2} \varphi}{\partial y^{2}}+\frac{\partial \varphi}{\partial y z^{2}}\right]^{\frac{1}{2}},
$$

Такий розгляд процесу розтікання струму $є$ правильним при числовому розв'язанні задачі для проходження струму в електроді [31,37]. Тоді тепло від об'ємного джерела тепла, яке діє в усьому розглянутому об'ємі електрода, знаходимо так:

$$
Q_{\text {об.д. }}=\rho[T(x, y, z, t)] j^{2}(x, y, z, t),
$$

Для розв'язання теплової задачі на електродах через рівняння балансу треба враховувати і тепловідведення. Так, у загальному випадку тепловідведення внаслідок зсуву фронту випаровування, можна записати у вигляді

$$
Q_{3 c . \phi .}=C_{v}[T(x, y, z, t)] V_{3 c . \phi .} \frac{\partial T(x, y, z, t)}{\partial x},
$$

де $C_{v}[T(x, y, z, t)]$ - теплоємність матеріалу електрода в цій точці при відповідній температурі $T(x, y, z, t)$, яка задається масивом з використанням експериментальних значень цієї величини або за допомогою лінійної екстраполяції; $V_{\text {ev.f }}$ - величина швидкості зсуву фронту випаровування для випадку, коли на поверхні електрода не виникає шар металу, перегрітого вище температури плавлення, тобто $T(0, y, z, t)<T_{\text {mil }}$, $\left(T_{\text {mil }}\right.$ - ефективна температура плавлення матеріалу електрода, що враховує витрати тепла на плавлення). Цю швидкість зсуву можна визначити так:

$$
V_{e v \cdot f}=\frac{1}{v} \sqrt{\frac{M}{2 \pi R T(0, y, z, t)}}\left[\exp \left(A-\frac{B}{T}\right)-P_{3}\right],
$$

де $A$ та $B$ - табульовані сталі [37]; $R$ - газова стала; $\gamma$ - густина матеріалу електрода; $M$ - атомна вага матеріалу електрода, що нагрівається; $P_{3}$ - тиск залишкових газів;

При виникненні на поверхні електрода шару перегрітого матеріалу реалізується френкелівський механізм і швидкість зміщення фрронту випаровування будемо знаходити так: 


$$
V_{e v . f}=V_{0} \exp \left(-\frac{T_{s}}{T(0, y, z, t)}\right),
$$

де $V_{0}$ та $T_{s}$ - швидкість зсуву фронту випаровування і температура поверхні плями при стаціонарному режимі випаровування, що визначаються рівнянням (13).

Для визначення теплового потоку, що відводиться від елементарного об'єму теплопровідністю матеріалу, скористаємося виразом

$$
Q_{\text {B.mn. }}=C_{v}[T(x, y, z, t)] \cdot \varepsilon[T(x, y, z, t)] \Delta T(x, y, z, t),
$$

де $\varepsilon-$ коефріцієнт температуропровідності.

Теплопідвід до поверхні плями призводить до підвищення густини теплового потоку внаслідок випромінювання плазми, який знаходимо за виразом:

$$
Q_{\text {b.n. }}=b_{n} \sigma T_{n}^{4},
$$

де $b_{n}$ - ступінь чорноти плазми; $\sigma$ - постійна Стефрана-Больцмана; $T_{n}$ температура плазми.

А значить тепловідведення від плями внаслідок випромінювання враховуємо за фрормулою Стефана-Больцмана:

$$
Q_{6}=b \sigma[T(0, y, z, t)]^{4},
$$

Зменшення густини теплового потоку на електроді внаслідок тепловідведення випаровуванням у загальному випадку визначаємо за формулою

$$
Q_{\text {Bn }}=F_{\text {Bn }} \gamma V_{\phi},
$$

де $F_{6 n}$ - прихована теплота випаровування; $V_{\phi}$ - швидкість зсуву фронту випаровування.

Причому, якщо температура поверхні менше температури правлення, то $V_{f}$ знаходимо за виразом (15).

Теплообмін між електродами і газом (наповнювачем) при достатніх витратах робочого тіла може бути описаний як конвективний:

$$
Q_{B b}=\alpha_{B 8} \Delta T_{\mathrm{lg}},
$$

де $\alpha_{68}-$ коефіцієнт тепловіддачі конвенцій; $T_{l g}$ - середня логарифмічна температура теплообміну.

Коефріцієнт тепловіддачі конвенцій в разі високих швидкостей руху газу в міжелектродному просторі може бути представлений так:

$$
\alpha_{68}=\frac{\lambda}{l_{0}} N_{u}=\frac{\lambda}{l_{0}} 0.0162\left(\frac{3600 l_{o}}{U}\right)^{0.02}\left(\frac{T_{g}}{T_{s}}\right)^{0.85} .
$$

де $N_{u}=0,016 P_{e}^{0,82}\left(\frac{T_{g}}{T_{s}}\right)^{0,035}$ - критерій Нуссельта, а $P_{e}=\frac{3600 V l_{0}}{U}-$ критерій Пеклі; $\lambda$ - коефіцієнт теплопровідності газу; $l_{0}$ - характерна довжина (довжина вставки) [37]; $V$ - швидкість газу; $U$ - кінематична в'язкість; $\rho$ - густина.

Тоді

$$
\Delta T_{\mathrm{lg}}=\frac{t_{g 1}-t_{g 2}}{\ln \left(t_{g 1}-T_{g}\right) /\left(t_{g 2}-T_{g}\right)},
$$


де $t_{g 1}=T_{g}+\left(A V_{g 1} / 2 g C_{p}\right)$ і $t_{g 2}=T_{g}+\left(A V_{g 2} / 2 g C_{p}\right)$ - температура на вході і на виході; $V_{g 1}, V_{g 2}$ - швидкість на вході та виході у міжелектродному просторі; $C_{p}$ теплоємність газу.

Теплообмін в районі плями буде здійснюватися також внаслідок переміщенню плями. Тепловий потік, що відводиться завдяки переміщенню плями, визначимо так:

$$
Q_{v . s p}=C_{v}[T(x, y, z, t)] V_{s p} \frac{\partial T(x, y, z, t)}{\partial y},
$$

де $V_{s p}$ - швидкість переміщення джерела тепла (швидкість електродинамічного зміщення або антиамперного руху для деяких режимів електродної плями).

3 урахуванням вищерозглянутих джерел і стоків тепла баланс енергії в елементарному об'ємі плями (рис. 1) запишемо у вигляді диференціального рівняння:

$$
\begin{aligned}
& C_{v}[T(x, y, z, t)] \frac{\partial T(x, y, z, t)}{\partial t}+C_{v}[T(x, y, z, t)] V_{n} \frac{\partial T(x, y, z, t)}{\partial y}=C_{v}[T(x, y, z, t)] \varepsilon[T(x, y, z, t)] \Delta T(x, y, z, t)+ \\
& +C_{v}[T(x, y, z, t)] V_{\text {gn. }} \frac{\partial T(x, y, z, t)}{\partial x}+\rho[T(x, y, z, t)] j^{2}(x, y, z, t)+\frac{B j_{i, e} \mu_{i, e}}{C_{v}[T(x, y, z, t)]} \frac{\partial E}{\partial x} .
\end{aligned}
$$

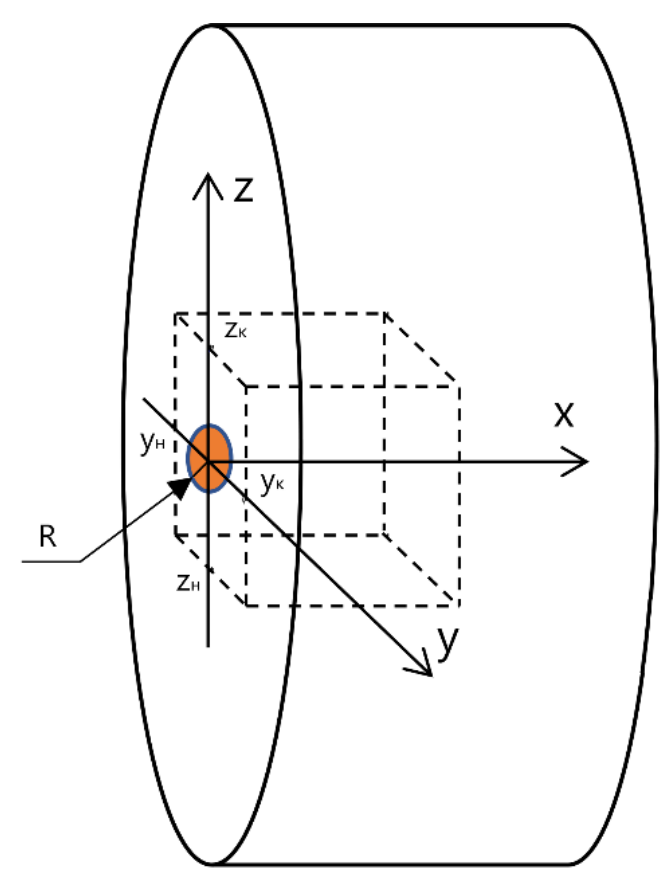

Рис. 1. Схема одиничного об'єму електрода поблизу електродної плями

Розглянемо граничні умови для цього рівняння, в яких будуть враховані поверхневе джерело тепла та змінення інтенсивності поверхневого джерела тепла внаслідок взаємовипромінювання плазма-електрод, а також відведення тепла з випаровуванним металом:

1) так при $t<T_{i}$

$$
-\frac{\partial T(x, y, z, t)}{\partial t}=\frac{Q_{1}}{\lambda}-\frac{Q_{b n}}{\lambda}+\frac{\sigma}{\lambda}\left[b_{p} \sigma T_{p}^{4}-b T^{4}(0, y, z, t)\right]-\frac{Q_{\text {bn }}}{\lambda},
$$


причому якщо розмір плями $\sqrt{z^{2}+\left(y-V_{p} t\right)^{2}} \leq R$, то $Q_{1}=Q_{s}$, а якщо $\sqrt{z^{2}+\left(y-V_{p} t\right)^{2}}>R$, то $Q_{1}=0$;

де $\mathrm{R}$ - радіус плями;

2) при $t>T_{l} Q=0$, граничні умови на поверхні $x_{e}, y_{s}, y_{e}, z_{s}, z_{e}$ можна записати в наступному вигляді:

$$
\begin{aligned}
& \text { якщо } t=T_{l}=t_{H} \text {, то } x_{H}=\sqrt{6 a t_{H}}, y_{H}=-R-\sqrt{6 a t_{H}}, y_{\kappa}=R+\sqrt{6 a t_{\kappa}}+V_{n} \tau_{n}, \\
& z_{H}=-R-\sqrt{a t_{H}}, z_{\kappa}=R+\sqrt{a t_{\kappa}}, \text { отже, } \\
& T\left(x_{H}, y, z, t\right)=T\left(x, y_{H}, z, t\right)=T\left(x, y_{\kappa}, z, t\right)=T\left(x, y, z_{H}, t\right)=T\left(x, y, z_{\kappa}, t\right)=T_{H} .
\end{aligned}
$$

Область простору електрода з координатами $\mathrm{x}_{\mathrm{H}}=0, \mathrm{y}_{\mathrm{H}}, \mathrm{y}_{\mathrm{K}}, \mathrm{z}_{\mathrm{H}}, \mathrm{z}_{\mathrm{K}}$ показана на рис 1.

Ці координати обмежують область простору, в якій розглядається задача теплопровідності. При цьому початкові умови будуть:

$$
t=0, T(x, y, z, 0)=T_{H} .
$$

Характер дії об'ємного джерела тепла визначається розв'язанням рівняння Лапласа (8) з подальшим обчисленням густини струму в даній точці електрода (11) та інтенсивності об'ємного джерела (12).

Розв'язання рівняння теплопровідності (24) дозволить визначити температурне поле поблизу плями на електроді, а інтегрування швидкості випаровування на поверхні електрода за подвоєний час їі життя, дасть кількість випареної маси:

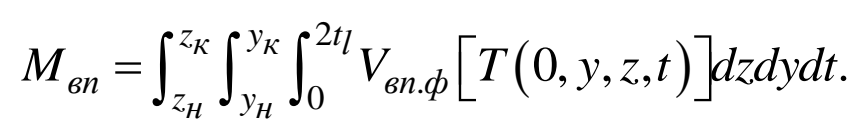

При експериментальних дослідженнях ерозії у металевих електродів практично на всіх режимах розрядження 3 електродною плямою спостерігаються викиди рідкого металу у вигляді крапель [31]. Але при використанні графрітових електродів викид матеріалу проходить у вигляді кластерів [29]. В теоретичних роботах, що стосуються ерозії, розглядається ціла низка варіантів викиду матеріалу електродів [10, 30]. Виходячи з цього, умовою викиду матеріалу електрода будемо вважати умову, коли тиск, створений силами, що викидають матеріал, перевищує тиск створений силами, які утримують його, з урахуванням їх напрямків. При цьому коефріцієнт ерозії для електродної плями визначається як відношення випарюваної маси $M_{e v}$ до величини заряду, що переноситься у плямі. Величину заряду визначимо як

$$
q_{3}=\int_{z_{H}}^{z_{\kappa}} \int_{y_{H}}^{y_{\kappa}} \int_{0}^{2_{t l}} j(0, y, z, t) d z d y d t
$$

де $j(0, y, z, t)=j_{e n}$, при $\sqrt{z^{2}+\left(y-V_{p} t\right)^{2}}>R$.

Тоді коефіцієнти ерозії знайдемо за виразом

$$
k_{1}=\frac{M_{6 n}}{q_{3}} .
$$




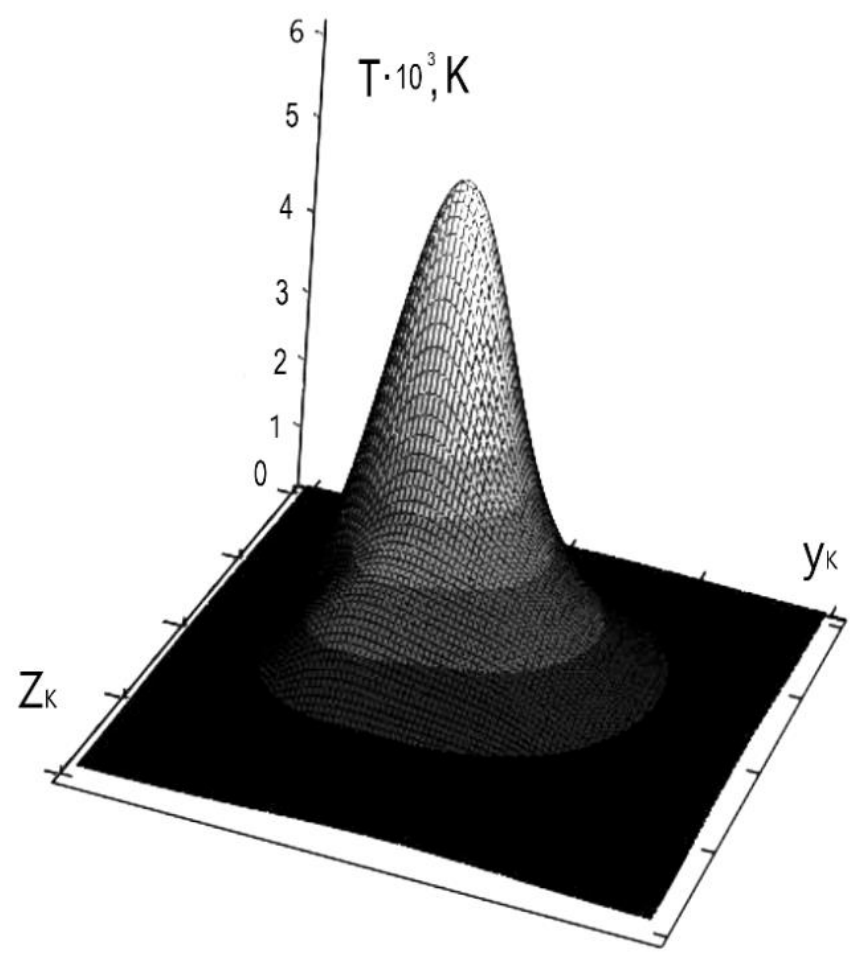

a

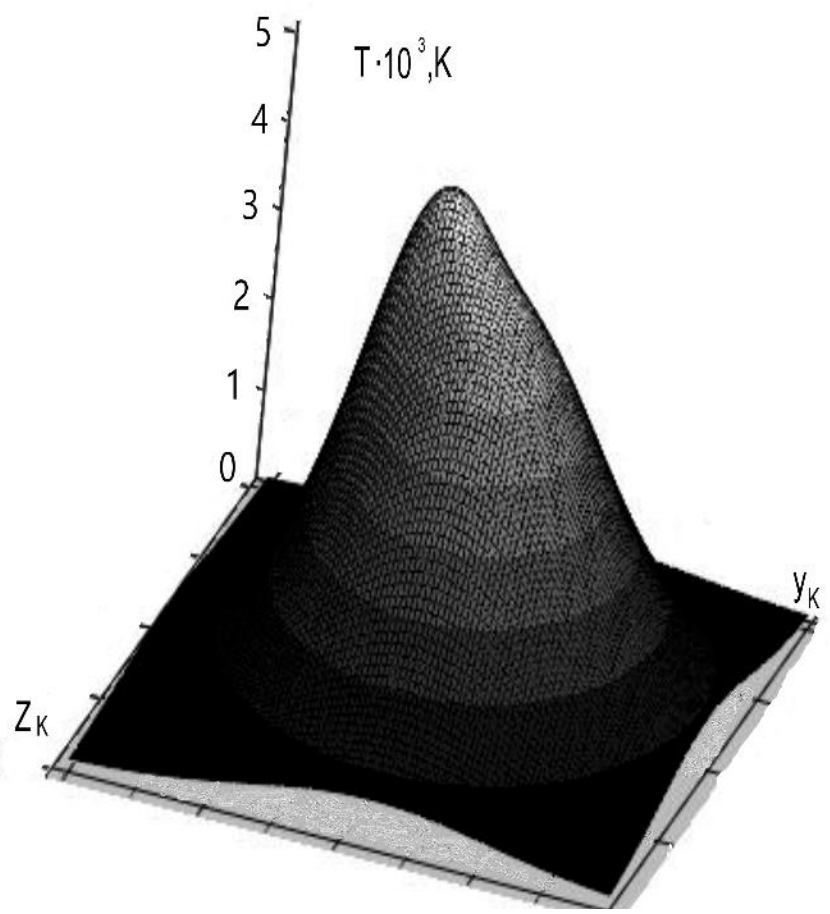

б

Рис. 2. Температурні поля

a - статична пляма катоду; б - рухома пляма катоду

2. Результати розрахунків 
За наведеною вище моделлю та алгоритмом було проведено розрахунки для графрітових електродів при технологічних умовах, необхідних для формування наноструктур у плазмовому середовищі [30, 33]. У результаті теоретичних розрахунків було отримано температурні поля поблизу рухомої та нерухомої плям (рис. 2, а, б), а також графік залежності коефіцієнта ерозії від часу життя плями як для катода (рис. 3, 4 ), так і для анода (рис. 5, 6).

Розрахунки виконувались для різної густини струму $10^{10} \ldots 10^{12} \mathrm{~A} / \mathrm{m}^{2} \mathrm{i}$ для різних швидкостей переміщення плям $1 \ldots 0,5 \cdot 10^{2} \mathrm{M} / \mathrm{c}$. Як видно із залежностей для анода при щільності густині менше $10^{10} \mathrm{~A} / \mathrm{m}^{2}$ розривів коефіцієнта ерозії немає, але при $10^{11} \mathrm{~A} / \mathrm{m}^{2}$ з'являються розриви на скінчену величину, що свідчить про викиди кластерів матеріалу.

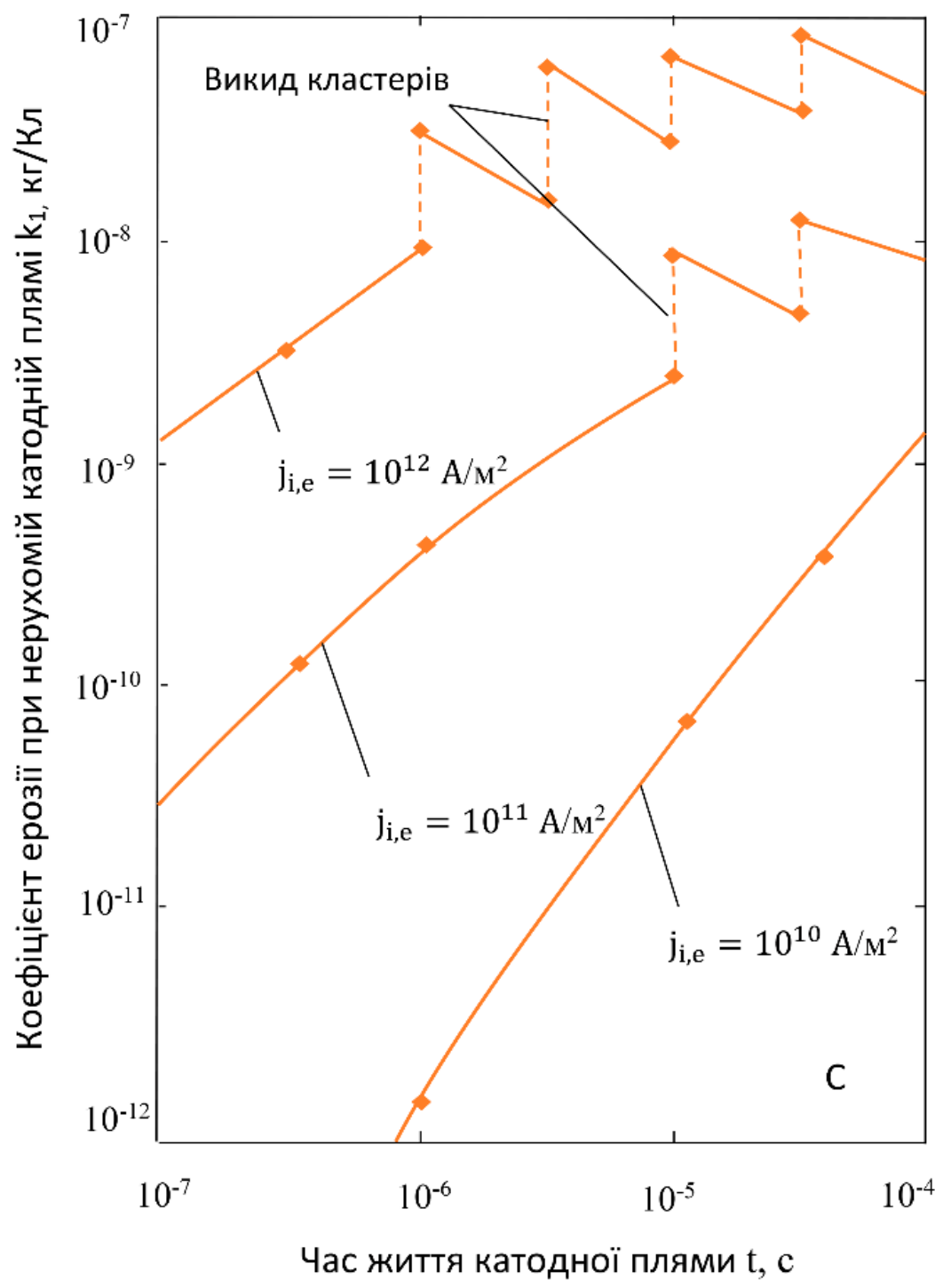

Рис. 3. Графрік залежності коефріцієнта ерозії від часу життя нерухомої плями на катоді

Графріки залежності коефріцієнта ерозії від часу життя для рухомих плям (рис. 5, 6) свідчать про те, що з підвищенням швидкості плями суттєво знижується коефіцієнт ерозії. Так, для при швидкості плями 50 м/с коефріцієнт ерозії зменшується на порядок. 
Відкриті інформаційні та комп'ютерні інтегровані технології, № 94, 2021

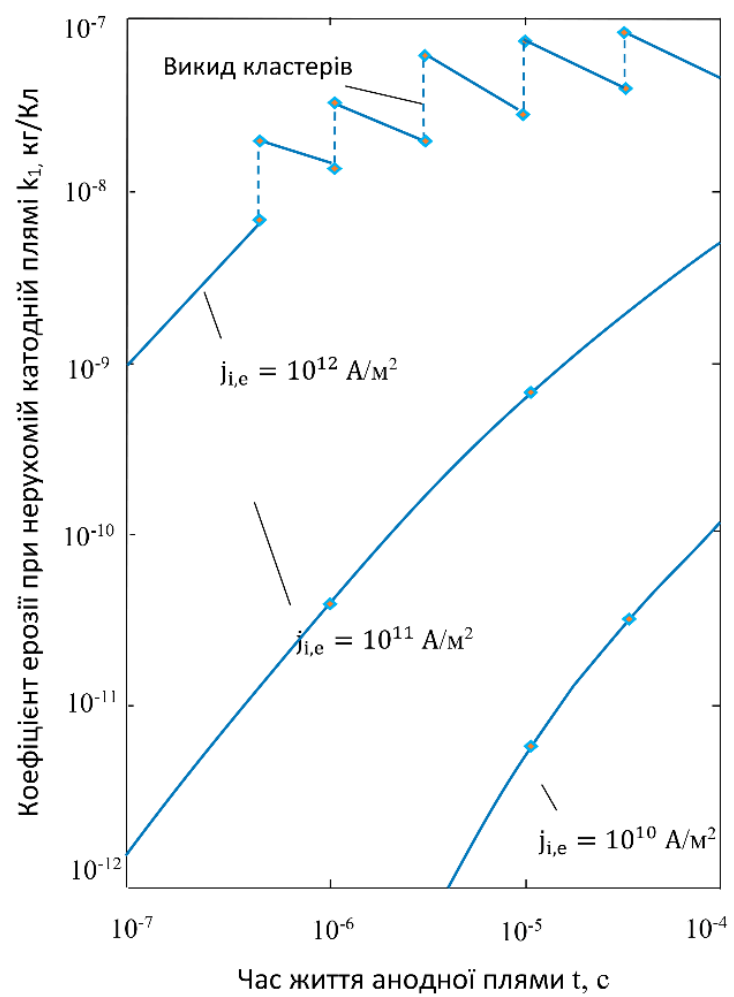

Рис. 4. Графрік залежності коефіцієнта ерозії від часу життя нерухомої плями на аноді

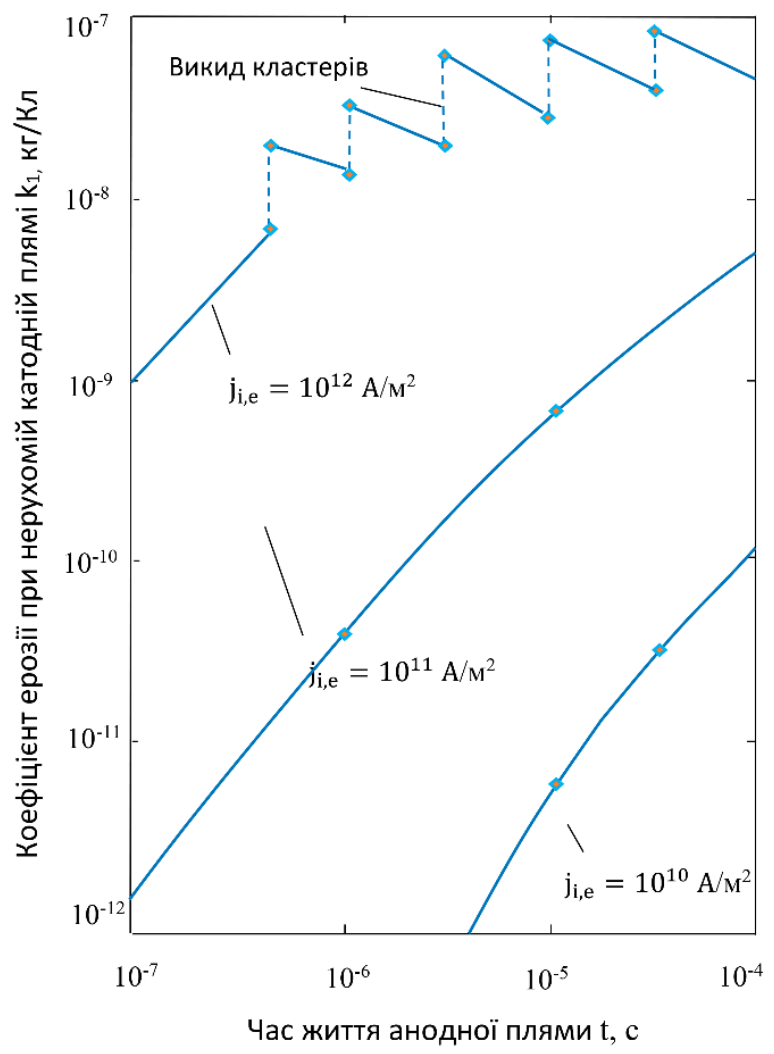

Рис. 5. Графрік залежності коефіцієнта ерозії від часу життя рухомої плями на катоді 


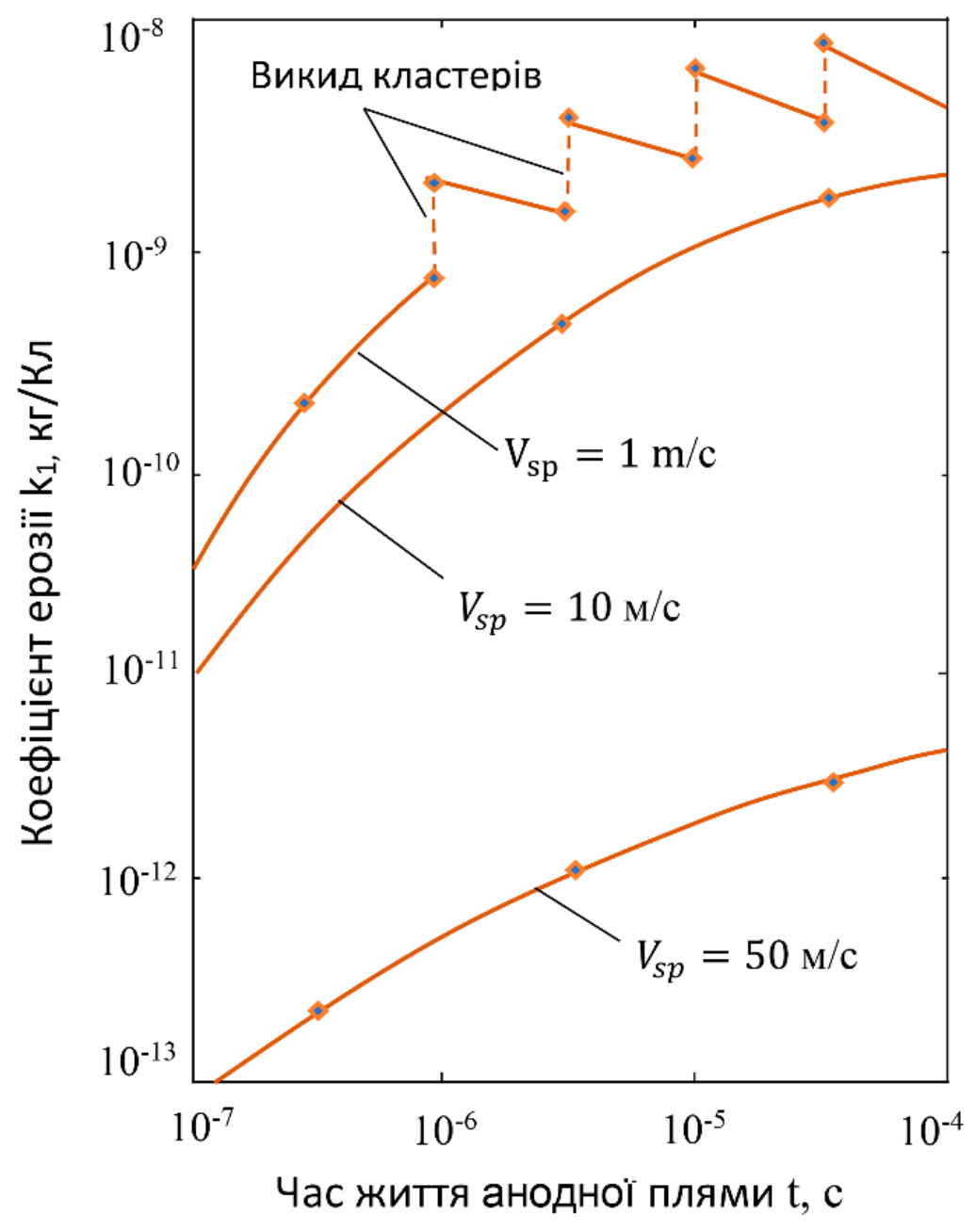

Рис. 6. Графрік залежності коефіцієнта ерозії від часу життя рухомої плями на аноді

\section{Висновки}

Для визначення граничних значень технологічних параметрів отримання наноструктур у вакуумній дузі на графрітових електродах було розглянуто тривимірну теоретичну модель ерозійних процесів у плямах електродів під час вакуумного розряду. Завдяки розробленій моделі було виконано розрахунки для графітових електродів. Отримано залежність коефіцієнта ерозії від часу житті плями та густини струму на електродах. Визначено, що при густині струму більше $10^{10} \mathrm{~A} / \mathrm{M}^{2}$ збільшується імовірність появи викиду матеріалу у вигляді кластерів, що буде перешкоджати появі рівномірних наноструктур. Залежності коефіцієнта ерозії від часу життя було отримано як для стаціонарної, так і для рухомої плям. Визначено залежність суттєвого зменшення коефіцієнта ерозії при підвищенні швидкості плям. Отримані теоретичні значення за густиною струму збігаються за порядком з відомими експериментальними значеннями [13,31]. Все це свідчить про адекватність моделі та можливості її використання для визначення критичних значень технологічних параметрів інших матеріалів електродів.

\section{Подяки}


Автор висловлює подяку Національному фронду досліджень України за підтримку (конкурс «Підтримка досліджень провідних та молодих учених», номер проекту 2020.02/0119).

\section{Список літератури}

1. Beilis, I.I. Thin Film Deposition by Plasma Beam of a Vacuum Arc with Refractory Anodes. / I. I. Beilis, R. Boxman, A. Pogrebnjak, V. Novosad // In: Advances in Thin Films, Nanostructured Materials, and Coatings. Lecture Notes in Mechanical Engineering. Springer, Singapore. - 2019. - P. 1-15.

2. Glukhov, O.V. Nanostructured Coatings Based on Amorphous Carbon and Gold Nanoparticles Obtained by the Pulsed Vacuum-arc Method / O.V. Glukhov, A.Ya. Kolpakov, M.G. Kovaleva, V.M. Beresnev, S.S. Manokhin, A.I. Poplavsky, A.N. Khmara, M.V. Mishunin, M.E. Galkina, J.V. Gerus, M.N. Yapryntsev, V.V. Sirota, O.V. Glukhov // Journal of nano- and electronic physics. - 2019. - Vol. 11, No. 4. P. 04019.

3. Wang, D. Nanosecond pulsed streamer discharges: II. Physics, discharge characterization and plasma processing. / D. Wang and T. Namihira // Plasma Sources Science and Technology. - 2020. - № 29. - P. 023001.

4. Перспективы применения лазерной обработки для создания наноструктур на РИ из «ВолКар» / Г. И. Костюк, Ю. В. Широкий / Вісник НТУ «ХПІ». Серія: Технології в машинобудуванні. - Харків: НТУ «ХПІ», 2017. - № 26(1248). - C. 60-65.

5. Zolotukhin, D. B. Optimization of discharge triggering in micro-cathode vacuum arc thruster for CubeSats. / D. B. Zolotukhin, M. Keidar // Plasma Sources Science and Technol.-2018. - № 27. - P. 1361-6595.

6. Levchenko, I. Recent progress and perspectives of space electric propulsion systems based on smart nanomaterials. / Levchenko, I., Xu, S., Teel, G., et all // Nat Commun. - 2018. - № 9. - P. 879.

7. Balanovskiy A. E. Digital visualisation of the process of heating and melting of metal in arc discharge with a non-consumable electrode, Welding International. - 2017.- № 31(6). - P. 467-476.

8. Babaeva, N. Y. The role of fast electrons in diffuse discharge formation: Monte Carlo simulation. / N. Y. Babaeva, C. J. Zhang, Q. X. Hou, et al// Plasma Sources Sci. Technol. - 2017. - № 26 (8).- P. 085008.

9. Nikolaev, A.G. Effect of the discharge parameters on the generation of deuterium ions in the plasma of a high-current pulsed vacuum arc with a composite zirconium deuteride cathode. / A.G. Nikolaev, E.M .Oks, V.P. Frolova et all // Tech. Phys. - 2017. - № 62. - Р. 701-707.

10. Белан, Н. В. Физические основы стойкости электродов плазменных ускорителей и технологических плазменных устройств / Н. В. Белан, Г. И. Костюк, Е. П. Мышелов. // Харьков. - 1986. - С. 205.

11. Medhisuwakul, N. Development and application of cathodic vacuum arc plasma for nanostructured and nanocomposite film deposition, N. Medhisuwakul, S. Pasaja, et all Surface and Coatings Technology. - 2013. - №29. - P. 36-41.

12. Timerkaev, B.A. Creation of Silicon Nanostructures in Electric Arc Discharge. / B. A. Timerkaev, B. R. Shakirov \& D. B. Timerkaeva // High Energy Chem. - 2019. - № 53. - P. 162-166. 
13. Beilis I. Cathode Spot Jets. Velocity and Ion Current. In: Plasma and Spot Phenomena in Electrical Arcs. Springer Series on Atomic, Optical, and Plasma Physics. - 2020. - P. 113.

14. Kostyuk, G. Efficiency and Performance of Milling Using Cutting Tools with Plates of a New Class. / G. Kostyuk, V. Popov, Y. Shyrokyi, H. Yevsieienkova // In: Tonkonogyi V. et al. (eds) Advanced Manufacturing Processes II. InterPartner 2020. Lecture Notes in Mechanical Engineering. Springer. - 2021. - № 2. - P. 598608.

15. Сысоев Ю. А. Проблемы ионно-плазменных технологий на основе вакуумно-дугового разряда и пути их решения / Ю. А. Сысоев // Авиационнокосмическая техника и технология. - 2011. - № 7. - С. 38-43.

16. Baranov, O. Current Distribution on the Substrate in a Vacuum Arc Deposition Setup. / O. Baranov, M. Romanov, // Plasma Processes and Polymers. 2008. - № 5. - P. 256.

17. Baranov, O. Control of ion density distribution by magnetic traps for plasma electrons. / O. Baranov, M. Romanov, J. Fang, U. Cvelbar, K. Ostrikov // Journal of Applied Physic. - 2012. - № 112 (7). - P. 073302.

18. Beilis, I. I. Anode Temperature Evolution in a Vacuum Arc with a Blackbody Electrode Configuration. / I. I. Beilis, Y. Koulik et all // in IEEE Transactions on Plasma Science. - 2017. - № 45 (8). - P. 234-236.

19. Anders, A. The evolution of ion charge states in cathodic vacuum arc plasmas: a review / A. Anders // Plasma Sources Science and Technology. - 2012. №21 (3). - P.458.

20. Beilis, I. I. Vacuum arc cathode spot grouping and motion in magnetic fields / I. I. Beilis // in IEEE Transactions on Plasma Science. - 2002. - № 30 (6). P. 2124-2132.

21. Yinghe, Ma Imaging and motion of cathode group spots during pulseenhanced vacuum arc evaporation / Yinghe Ma, Chunzhi Gong, Xiubo Tian, Paul K. Chu // Vacuum. - 2017. - № 139. - P, 37-43.

22. Hermanns, P. Formation and behaviour of plasma spots on the surface of titanium film / P. Hermanns, F. Kogelheide, V. Bracht, S. Rie, F. Krüger, S. Böddeker // Journal of Physics D: Applied Physics. - 2020. - № 54 (8). - P 085203.

23. Böddeker S. Anode spots of low current gliding arc plasmatron / S. Boddeker, V. Bracht, P. Hermanns, S. Groeger, F. Kogelheide, N. Bibinov, P. Awakowicz, //Plasma Sources Science and Technology. - 2020. - № 29 (8). P. 1-10.

24. Nikolaev, A.G. Effect of the discharge parameters on the generation of deuterium ions in the plasma of a high-current pulsed vacuum arc with a composite zirconium deuteride cathode. /, A.G. Nikolaev, E.M Oks, V.P. Frolova, et // Tech. Phys. - 2017. - № 62. - P. 701-707.

25. Zhou, Z. Direct observation of vacuum arc evolution with nanosecond resolution. / Z. Zhou, A. Kyritsakis, Z. Wang, et al. //Sci Rep. - 2019. - № 9. - P. 7814.

26. Mesyats, G. A. Ecton Mechanism of the Cathode Spot Phenomena in a Vacuum Arc / G. A. Mesyats // in IEEE Transactions on Plasma Science. - 2013. № 41 (4). - P. 676-694.

27. Keidar, M, Arc plasma synthesis of carbon nanostructures: where is the frontier? M. Keidar, A. Shashurin, J. Li, O. Volotskova, M. Kundrapu, T. S. Zhuang. Journal of Physics D: Applied Physics. - 2011. - № 44(17). - P. 174006. 
28. Shyrokyj, Y.V. Simulation of an arc discharge on copper cathode for the generation of nanostructures / Y.V. Shyrokyi, G. I. Kostyuk //Open Information and Computer Integrated Technologies, - № 91. - 2021. - C. 62-76.

29. Barengolts, S. A. Effect of the Nanostructured Layer Thickness on the Dynamics of Cathode Spots on Tungsten, / S. A. Barengolts, V. G. Mesyats, M. M. Tsventoukh, S. Kajita, D. Hwangbo and N. Ohno // in IEEE Transactions on Plasma Science. - 2018. - №46 (11). - P. 4044-4050.

30. Rao, L. Vacuum arc velocity and erosion rate measurements on nanostructured plasma and HVOF spray coatings. / L. Rao, R. J Munz and J.L. Meunier, // Journal of Physics D: Applied Physicsю - 2007. - №14 (40). P. 4192-4201.

31. Параметры катодных и анодных пятен в технологических плазменных устройствах (эксперимент) / Г.И. Костюк, Ю.В. Широкий, А.Н. Костюк, И.В. Леонова // Открытые информационные и компьютерные технологии. - 2013, - № 60ю - С.155-164.

32. Hwangbo, D. Transition in velocity and grouping of arc spot on different nanostructured tungsten electrodes / D. Hwangbo, S. Kajita, S. A. Barengolts, M. M. Tsventoukh, N. Ohno // Results in Physics. - 2014. - № 4, P. 33-39.

33. Shin Kajita, Noriyasu Ohno, Shuichi Takamura, Yoshiyuki Tsuji, Direct observation of cathode spot grouping using nanostructured electrode, Physics Letters Aю - 2009. - № 373 (46). - P. 63-75.

34. Levchenko, I. Ion deposition in a crossed $E \times B$ field system with vacuum arc plasma sources. / I. Levchenko, M. Romanov, O. Baranov, M. Keidar // Vacuum. - 2003. - № 72(3). - P. 335-344.

35. Baranov, O.O. Effect of ion current density on the properties of vacuum arc-deposited TiN coatings. / O.O. Baranov, J. Fang, A. E. Rider, S. Kumar, K Ostrikov // IEEE Transactions on Plasma Science. - 2013. - № 41(12). - P. 36403644.

36. Beilis, I. I.: Cathode Spot Development on a Bulk Cathode in a Vacuum Arc. / I. Beilis // I. IEEE Transactions on Plasma Science. - 2013. №41(8). - P.1979_ 1986.

37. Особенности теоретического рассмотрения процессов В электродных пятнах вакуумного разряда / ГИ Костюк, ЮВ Широкий, АН Костюк // Открытые информационные и компьютерные технологии. - 2013. - № 60. C.128-141.

\section{References}

1. Beilis I.I. Thin Film Deposition by Plasma Beam of a Vacuum Arc with Refractory Anodes. I. I. Beilis, R. Boxman, A. Pogrebnjak, V. Novosad [ In: Advances in Thin Films, Nanostructured Materials, and Coatings. Lecture Notes in Mechanical Engineering. Springer, Singapore]. no 2019, pp. 1-15.

2. Glukhov O.V. Nanostructured Coatings Based on Amorphous Carbon and Gold Nanoparticles Obtained by the Pulsed Vacuum-arc Method, O.V. Glukhov, A.Ya. Kolpakov, M.G. Kovaleva, V.M. Beresnev, S.S. Manokhin, A.I. Poplavsky, A.N. Khmara, M.V. Mishunin, M.E. Galkina, J.V. Gerus, M.N. Yapryntsev, V.V. Sirota, O.V. Glukhov [ Journal of nano- and electronic physics], 2019, no. 4, pp.04019.

3. Wang, D. Nanosecond pulsed streamer discharges: II. Physics, discharge characterization and plasma processing. D. Wang and T. Namihira [ 
Plasma Sources Science and Technology], 2020, no 29, pp. 023001.

4. Kostyuk G. Y`Perspekty'vы pry'meneny'ya lazernoj obrabotky` dlya sozdany'ya nanostruktur na $R Y^{\prime} y^{\prime} z$ "VolKar / G. Y'. Kostyuk, Yu.V. Shyrokyj [Vestnyk Nacyonalnogo texnycheskogo unyversyteta "XPY'»: sbornyk nauchnih trudov Temat. vsp. : Texnologyy v mashynostroenyy. -"]. Xarkov: NTU "XPY", 2017. - № 26(1248). - C. 60-65. (In Russian)

5. Zolotukhin D. B. Optimization of discharge triggering in micro-cathode vacuum arc thruster for CubeSats. D. B. Zolotukhin, M. Keidar [ Plasma Sources Science and Technologi ], 2018, no. 27, pp. 1361-6595.

6. Levchenko I. Recent progress and perspectives of space electric propulsion systems based on smart nanomaterials. Levchenko, I., Xu, S., Teel, G., et all [ Nat Commun.], 2018, no.9, pp. 879.

7. Balanovskiy A. E. Digital visualisation of the process of heating and melting of metal in arc discharge with a non-consumable electrode [ Welding International ], 2017, no 31(6), pp. 467-476.

8. Babaeva, N. Y. The role of fast electrons in diffuse discharge formation: Monte Carlo simulation. N. Y. Babaeva, C. J. Zhang, Q. Xю Hou, et all [ Plasma Sources Sciyns Technology ], 2017, no. 26 (8), pp. 085008.

9. Nikolaev, A.G. Effect of the discharge parameters on the generation of deuterium ions in the plasma of a high-current pulsed vacuum arc with a composite zirconium deuteride cathode. A.G. Nikolaev, E.M. Oks, V.P. Frolova et all [ Tech. Physics], 2017, no. 62, pp. 701-707.

10. Belan N.V. Fyzycheskye osnovы stojkosty эlektrodov plazmennыx uskorytelej y texnologycheskyx plazmennыx ustrojstv. Belan N.V., Kostyuk G. Y., Mushelov E.P., Xarkov, 1986, p. 205. (In Russian)

11. Medhisuwakul, N. Development and application of cathodic vacuum arc plasma for nanostructured and nanocomposite film deposition N. Medhisuwakul, S. [ Pasaja, et all Surface and Coatings Technology ], 2013, no. 29, pp 36-41.

12. Timerkaev, B.A. Creation of Silicon Nanostructures in Electric Arc Discharge. B. A. Timerkaev, B. R. Shakirov \& D. B. Timerkaeva [High Energy Chemical], 2019, no 53, pp. 162-166.

13. Beilis I. Cathode Spot Jets. Velocity and Ion Current. In: Plasma and Spot Phenomena in Electrical Arcs. [Springer Series on Atomic, Optical, and Plasma Physics ], 2020, p. 113.

14. Kostyuk G. Y. Efficiency and Performance of Milling Using Cutting Tools with Plates of a New Class. G. Kostyuk, V. Popov, Y. Shyrokyi, H. Yevsieienkova [ In: Tonkonogyi V. et al. (eds) Advanced Manufacturing Processes II. InterPartner 2020. Lecture Notes in Mechanical Engineering. Springer ], 2021, no 2, pp. 598-608.

15. Sыsoev Yu. A. Problemb yonno-plazmennыx texnologyj na osnove vakuumno-dugovogo razryada y` puty` yx reshenyya Yu. A. Susoev [Avyacyonnokosmycheskaya texnyka y` texnologyya.] 2011, no 7, pp. 38-43. (In Russian)

16. Baranov, O. Current Distribution on the Substrate in a Vacuum Arc Deposition Setup. O. Baranov, M. Romanov, [ Plasma Processes and Polymers.], 2008, no. 5, p. 256.

17. Baranov O. Control of ion density distribution by magnetic traps for plasma electrons. O. Baranov, M. Romanov, J. Fang, U. Cvelbar, K. Ostrikov [ 
Journal of Applied Physic], 2012, no. 112 (7), pp. 073302.

18. Beilis, I. I. Anode Temperature Evolution in a Vacuum Arc with a Blackbody Electrode Configuration. I. I. Beilis, Y. Koulik et all [ in IEEE Transactions on Plasma Science], 2017, no 45 (8), pp. 234-236.

19. Anders A. The evolution of ion charge states in cathodic vacuum arc plasmas: a review, A. Anders [Plasma Sources Science and Technology], 2012, no. 21 (3).

20. Beilis, I. I. Vacuum arc cathode spot grouping and motion in magnetic fields I. I. Beilis [ in IEEE Transactions on Plasma Science ], 2002, - №30 (6). - P 2124-2132.

21. Yinghe Ma Imaging and motion of cathode group spots during pulseenhanced vacuum arc evaporation. Yinghe Ma, Chunzhi Gong, Xiubo Tian, Paul K. Chu [ Vacuum], 2017, no 139, pp. 37-43.

22. Hermanns, P. Formation and behaviour of plasma spots on the surface of titanium film. P. Hermanns, F. Kogelheide, V. Bracht, S. Rie, F. Krüger, S. Böddeker [ Journal of Physics D: Applied Physics ], 2020, no 54 (8), pp. 085203.

23. Böddeker S. Anode spots of low current gliding arc plasmatron. S. Böddeker, V. Bracht, P. Hermanns, S. Groeger, F. Kogelheide, N. Bibinov, P. Awakowicz. [ Plasma Sources Science and Technology], 2020, no. 29 (8), pp. 1-10.

24. Nikolaev, A.G. Effect of the discharge parameters on the generation of deuterium ions in the plasma of a high-current pulsed vacuum arc with a composite zirconium deuteride cathode. A.G. Nikolaev, E.M Oks, V.P. Frolova, et all [ Tech. Phys.], 2017, no 62, pp. 701-707.

25. Zhou Z. Direct observation of vacuum arc evolution with nanosecond resolution. Z. Zhou, A. Kyritsakis, Z. Wang, et all. [Sci Rep.], 2019, no. 9. pp. 7814.

26. Mesyats, G. A. Ecton Mechanism of the Cathode Spot Phenomena in a Vacuum Arc [ in IEEE Transactions on Plasma Science], 2013, no. 41 (4), pp. 676694.

27. Keidar, M, Arc plasma synthesis of carbon nanostructures: where is the frontier? M. Keidar, A. Shashurin, J. Li, O. Volotskova, M. Kundrapu, T. S. Zhuang. [ Journal of Physics D: Applied Physics ], 2011, no. 44(17) pp. 174006.

28. Shyrokyj Y.V. Simulation of an arc discharge on copper cathode for the generation of nanostructures. Y.V. Shyrokyi, G. I. Kostyuk [ Open Information and Computer Integrated Technologies ], 2021, no. 91, pp. 62-76.

29. Barengolts, S. A. Effect of the Nanostructured Layer Thickness on the Dynamics of Cathode Spots on Tungsten. S. A. Barengolts, V. G. Mesyats, M. M. Tsventoukh, S. Kajita, D. Hwangbo and N. Ohno [ in IEEE Transactions on Plasma Science ], 2018, no 46 (11), pp. 4044-4050.

30. Rao L. Vacuum arc velocity and erosion rate measurements on nanostructured plasma and HVOF spray coatings. L. Rao, R. J Munz and J.-L. Meunier [ Journal of Physics D: Applied Physics], 2007, no.14 (40), pp. 4192-4201.

31. Kostyuk G. Y'. Parametrb katodnыx $y^{\prime}$ anodnыx pyaten $v$ texnologycheskyx plazmennыx ustrojstvax (эkspery 'ment) /G. Y`. Kostyuk, Yu.V. Shyrokyj, A.N. Kostyuk, Y. V. Leonova [ Open Information and Computer Integrated Technologies ], 2013, no. 60, pp.155-164. (In Russian)

32. Hwangbo D. Transition in velocity and grouping of arc spot on different nanostructured tungsten electrodes, D. Hwangbo, S. Kajita, S. A. Barengolts, M. M. 
Tsventoukh, N. Ohno [ Results in Physics ], 2014, no. 4, pp. 33-39.

33. Shin Kajita, Direct observation of cathode spot grouping using nanostructured electrode, Shin Kajita, Noriyasu Ohno, Shuichi Takamura, Yoshiyuki Tsuji [ Physics Letters A ], 2009, no. 373 (46). - P. 2044-2050

34. Levchenko I. Ion deposition in a crossed $E \times B$ field system with vacuum arc plasma sources. I. Levchenko, M. Romanov, O. Baranov, M. Keidar [ Vacuum ], 2003, no 72(3), pp. 335-344.

35. Baranov O.O. Effect of ion current density on the properties of vacuum arc-deposited TiN coatings. O. O. Baranov, J. Fang, A. E. Rider, S. Kumar, K Ostrikov [ IEEE Transactions on Plasma Science ], 2013, no. 41(12), pp. 3640-3644.

36. Beilis, I. I. Cathode Spot Development on a Bulk Cathode in a Vacuum Arc. I. Beilis I. [ IEEE Transactions on Plasma Science], 2013, no 41(8), pp.19791986.

37. Kostyuk G Y. Osobennosty teoretycheskogo rassmotrenyya processov v эlektrodnыx pyatnax vakuumnogo razryada G. I. Kostyuk, Y.V. Shyrokyi, A.N. Kostyuk [ Otkrыtыe ynformacyonnыey` kompyuternыe texnology`y], 2013, no 60, pp 128-141. (In Russian).

Надійшла до редакції 11.12.2021, розглянута на редколегії 11.12.2021.

\section{Modeling of electroerosion processes on graphite electrodes in the formation of nanostructures in a plasma medium}

The theoretical model of erosion processes in electrode spots during vacuum discharge during nanostructure formation is developed in the work. In this model the sources and drains of heat in electrode spots are considered in detail. Thus, the heat flux density generated by ions taking into account the emission cooling, reverse electric current and Nottingham heat is taken into account for the cathode, and both positive anode and negative potential declines are considered in describing the surface heat source for the anode. The distribution of current density in the element of the considered electrode volume was considered in sufficient detail for describing the volumetric heat source. Heat transfer from plasma radiation and convective heat transfer, and heat dissipation due to the shift of the plasma evaporation front and its radiation were considered for a more comprehensive description of the heat balance equation. The heat flux due to the movement of the stain was also taken into account. Thanks to the proposed model, the temperature fields near the spots and the rate of evaporation of the material during the life of the spot were determined, which allowed to determine the erosion coefficient for the electrode spot. According to the proposed model, calculations were performed for graphite electrodes. The dependence of the erosion coefficient on the lifetime of the spot and the current density at the electrodes is obtained. It is determined that at current density of more than $10^{11} \mathrm{~A} / \mathrm{m}^{2}$ the probability of material emission in the form of clusters increases, which will prevent the appearance of nanostructures. Dependences of the erosion coefficient on the lifetime were obtained for both stationary and moving spots. The obtained dependences indicate the significant decrease in the erosion coefficient with increasing velocity of the spots. The determined theoretical values of current density coincide in order with the experimental values. The model can be used to determine 
the critical values of technological parameters in obtaining nanostructures for different electrode materials.

Key words: electrodes, vacuum arc, electrode spots, electropulse erosion, nanostructures.

\section{Відомості про автора:}

Широкий Юрій Вячеславович - кандидат технічних наук, доцент, кафедри теоретичної механіки, машинознавства та роботомеханічних систем, Національний аерокосмічний університет ім. М. Є. Жуковського «Харківський авіаційний інститут» м. Харків, Україна; i.shyrokyi@khai.edu; ORCID: 0000-0002-4713-0334

\section{About the Author:}

Shyrokyi Yurii - Doctor of Philosophy, Assistant-Professor, Head of Department of Theoretical Mechanics, Engineering and Robomechanical Systems, National Aerospace University "Kharkiv Aviation Institute", Kharkiv, Ukraine; i.shyrokyi@khai.edu; ORCID: 0000-0002-4713-0334 